\title{
Fuera de lugar: Undocumented Students, Dislocation, and the Search for Belonging
}

\author{
Blanca Minerva Torres-Olave \\ Loyola University Chicago, btorresolave@luc.edu \\ Mark Torrez \\ Loyola University Chicago, mtorrez@luc.edu \\ Kelly N. Ferguson \\ Loyola University Chicago, kferguson@luc.edu
}

Amy Bedford

Loyola University Chicago

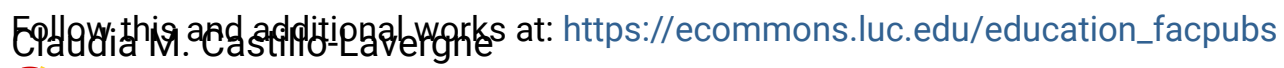

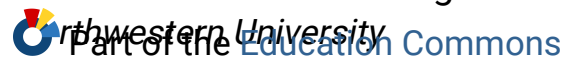

Author Manuscript

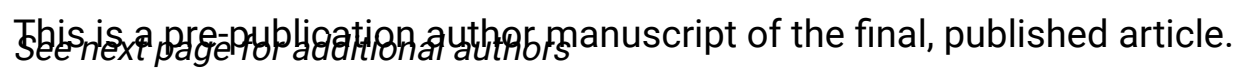

\section{Recommended Citation}

Torres-Olave, Blanca Minerva; Torrez, Mark; Ferguson, Kelly N.; Bedford, Amy; Castillo-Lavergne, Claudia M.; Robles, Karla; and Chang, Aurora. Fuera de lugar: Undocumented Students, Dislocation, and the Search for Belonging. Journal of Diversity in Higher Education, , : , 2020. Retrieved from Loyola eCommons, Education: School of Education Faculty Publications and Other Works, http://dx.doi.org/ $10.1037 /$ dhe0000182

This Article is brought to you for free and open access by the Faculty Publications and Other Works by Department at Loyola eCommons. It has been accepted for inclusion in Education: School of Education Faculty Publications and Other Works by an authorized administrator of Loyola eCommons. For more information, please contact ecommons@luc.edu.

\section{(c) (i) $\odot$}

This work is licensed under a Creative Commons Attribution-Noncommercial-No Derivative Works 3.0 License. (c) National Association of Diversity Officers in Higher Education, 2020. 


\section{Authors}

Blanca Minerva Torres-Olave, Mark Torrez, Kelly N. Ferguson, Amy Bedford, Claudia M. Castillo-Lavergne, Karla Robles, and Aurora Chang 


\begin{abstract}
This article presents findings from a Youth Participatory Action Research (YPAR) study on the experiences of six undocumented college students at a community college in the Midwest United States. We focused on two main research questions: What are some of the key developmental experiences of undocumented youth? What is the impact of these experiences on the students' identity and sense of belonging in educational spaces, especially as they transition to college? The findings illustrate the experiences of the six participant co-researchers (PCRs) as they navigated the messy, fragile, and shifting nature of belonging. A common thread in their narratives was the recurrence across their young lives of moments of dislocation (or "being-outof-place") associated with their undocumented status. These moments of dislocation barred these undocumented students from fully inhabiting both educational and non-educational spaces; additionally, they affected their ability to develop a sense of belonging as they transitioned to the college environment. Dislocation entails a degree of vulnerability and liminality that is not necessarily encompassed in current models of student development theory, nor considered in institutional support structures created with majority-population students in mind. We argue that institutional agents require sensitivity to the multiple types of dislocation that undocumented youth may experience within and beyond educational settings.
\end{abstract}

Keywords: Undocumented students, belonging, college, citizenship, student development 
Fuera de Lugar: Undocumented Students, Dislocation, and the Search for Belonging

The ache for home lives in all of us, the safe place where we can go as we are and not be questioned.

-Maya Angelou

The need to belong is innate, profound, and permeates most meaningful aspects of human activity, from cradle to grave. The primacy of belonging is well-evidenced across multiple bodies of scholarship as a fundamental human motivation that influences individual behavior, development, and social interaction. Consequently, barriers to, or severe, sustained disruptions in our sense of belonging (to places, communities, and so on) can significantly impact critical life outcomes such as education and employment, as well as mental, emotional, and physical wellbeing (Hausmann, Schofield, \& Woods, 2007; Ostrove \& Long, 2007; Strayhorn, 2012). For marginalized populations, such as undocumented students in the United States, belonging is not only about subjective feelings of "fitting in," but about how powerful others define legitimate membership to spaces according to norms or expectations both overt and formalized (e.g. citizenship, having "papeles"), as well as covert and intimate, such as those concerning the "appropriate" performance of the self, denoting one's insider or outsider status from one space to the next. In other words, “belonging” entails a condition in which one's presence in a space is possible, desirable, and perceived as legitimate. This condition is often at odds with the experience of undocumented youth, who live with the severe legal and social contradictions arising from growing up in the United States-yet without full participation U.S. society (Negrón-Gonzalez, 2014). In this sense, undocumented youth in the United States live with a 
liminal illegality status during their childhood, during which they are seen as legitimate students in K-12 public schools, but as illegitimate tresspassers - undeserving of full participation or protection —in nearly all other areas of government (Gonzalez, 2007). Liminality has been theorized as "the transitional moment between spheres of belonging when social actors no longer belong to the group they are leaving behind and do not yet fully belong in their new social sphere" (Suárez-Orozco, Bang, \& Kim, 2011, p. 444). The literature on the impact of legal status on undocumented youth in the United States consistently discusses their liminal status, caught between legality and illegality (Abrego, 2011; Gonzalez, 2007; Gonzalez, 2011; Heeren, 2015; Suárez-Orozco et al., 2011). Further layers of complexity in this liminal status become evident when we consider the diversity within this population, both in terms of the broad spectrum of immigration statuses comprising this population (e.g. DACA, non-DACA), as well as in the multiple, intersecting identities held by youth of undocumented status, which can play a significant role in shaping their experiences in various spaces and communities.

This article presents findings from a Youth Participatory Action Research (YPAR) study on the experiences of six undocumented college students at a community college in the Midwest. This study centered on two primary research questions: What are some of the key developmental experiences of undocumented youth? What is the impact of these experiences on the students' identity and sense of belonging in educational spaces, especially as they transition from high school to college, and as they navigate the first year in college? Our findings offer a textured account of the developmental experiences of the six participant co-researchers (PCRs) as they negotiated the messy, fragile, and shifting nature of belonging. A common thread in their narratives was the recurrence across of moments of dislocation (or "being-out-of-place") associated with their undocumented status. These moments of dislocation often barred these 
undocumented youth from fully inhabiting educational spaces and beyond, affecting their ability to develop a sense of belonging as they transitioned to the college environment.

In the course of this inquiry, the PCR's narratives inevitably transcended the neat, timebound academic category of "undocumented college student" — and instead took them back to past events in making sense of current experiences in higher education. As the co-authoring team, this required us to similarly expand our frames of mind and cut across academic siloes to honor their lived experiences. To that end, we draw on multidisciplinary perspectives on belonging (college student development, cultural geography, critical theory) to advance a layered or bricolage (Denzin \& Lincoln, 2000) examination of the "unique developmental challenges and experiences" of undocumented college students across the ecological lifespan (Patton, Renn, Guido, \& Quaye, 2016, p. 339). This lifespan framework allowed us to explore how undocumented students make meaning of their migration experiences, as well as consider the developmental implications of facing such adversity — as manifest in the educational pathways and developmental transitions of emerging adulthood in the United States (Gonzales, 2011; Muñoz \& Alleman, 2016).

The rest of the article is organized as follows. First, we discuss the notion of "belonging" in the student development literature, paying particular attention to where the scholarship must be advanced to better account for the experience of undocumented students. We then describe the YPAR methodology for the study and introduce our main findings, followed by a discussion and concluding remarks. We provide recommendations for changes in policy and practice to incorporate the voices and experiences of undocumented college students in higher education. 


\section{Literature Review}

The concept of belonging has received growing attention in the higher education literature, where it is positioned as a vital factor in college student experiences and outcomes such as learning, development, persistence, and overall success (Patton et al., 2016; Quaye \& Harper, 2014; Strayhorn, 2012). In the context of college, sense of belonging refers to "students" perceived social support on campus, a feeling or sensation of connectedness, the experience of mattering or feeling cared about, accepted, respected, valued by, and important to the group (e.g., campus community) or others on campus (e.g., faculty, peers)" (Strayhorn, 2012, p. 3).

Moreover, belonging is a relational construct. The sense that one matters or belongs is cultivated through an individual's position and relationships within a particular group or greater community (Strayhorn, 2019). The presence of positive interpersonal relationships and support networks with peers, family, and institutional agents fosters feelings of connection, mattering, validation, and empowerment — all of which bolster sense of belonging (Hurtado, Alvarado, \& GuillermoWann, 2015; Strayhorn, 2019). In turn, the absence of a sense of belonging can lead to feelings of alienation with significant consequences for college student learning, development, persistence, and overall success.

Scholars have thus argued that a sense of belonging may be understood through a lens of developmental ecology, which considers "the processes and conditions that govern the lifelong course of human development in the actual environments in which human beings live" (Bronfenbrenner, 1994, p. 37). The developmental impact of person-environment interactions has been used to understand family and educational processes across the lifespan (e.g., Fish \& Syed, 2018; Renn \& Arnold, 2003). Likewise, cultural ecologists have demonstrated that developmental outcomes among immigrant children are tied to contextual demands in their 
families, schools, and neighborhoods (Suárez-Orozco, Bang, \& Kim, 2011; Suárez-Orozco, 1987), and that aspects such as school persistence are similarly influenced by socio-cultural context and dynamics (Rubin, 2012; Stephens, Fryberg, Markus, Johnson, \& Covarrubias, 2012).

In this regard, educational opportunity within the United States is conditional to the degree to which students 'fit' into the system of education's dominant norms of a particular campus culture (Hausmann et al., 2007; Hurtado et al. 2015; Stephens et al., 2012; Ostrove \& Long, 2007; Strayhorn, 2012; Vaccaro \& Newman, 2016). Thus developing a sense of belonging can be especially challenging for students from marginalized populations (Hurtado et al., 2015; Johnson et al., 2007; Ostrove \& Long, 2007; Stephens et al., 2012; Strayhorn, 2012), who must navigate largely homogenous college environments largely structured to reflect and perpetuate dominant identities and cultural ideologies. For undocumented youth in the United States, "fitting into" the dominant norms of the educational system can be particularly complicated. As a population continuously denied educational opportunities by shifting laws, financial barriers, and institutional attitudes, undocumented youth face a pervasive status of "suspended illegality" (Gonzalez, 2011). This status marks them as both legitimately occupying certain spaces, such as public schools, but simultaneously barred from all other protections of civic membership, and from ordinary aspects of day-to-day adult life (e.g., obtaining a driver's license, buying a cell phone, or applying for jobs) to the terrifying possibility of deportation (Abrego, 2006; Gonzalez, 2011; Heeren, 2015).

The literature on the impact of legal status on undocumented youth in the United States consistently discusses their liminality, that is, "the transitional moment between spheres of belonging when social actors no longer belong to the group they are leaving behind and do not yet fully belong in their new social sphere" (Suárez-Orozco et al., 2011, p. 444). Whereas most 
high school students view graduation as representing the freedom to choose their future, for the close to 98,000 undocumented students who graduate from high school each year (Zhong \& Batalova, 2019), this rite of passage represents an inevitable confrontation with this liminality; the "paradoxical middle ground between legality and illegality, loosely tethered to this country by humanitarian concern or prosecutorial discretion" (Heeren, 2015, p. 1120).

From a perspective of student development, the tension between the affective dimension of belonging — the "longing" for membership (Probyn, 1996) — and the formal structures of belonging, namely citizenship and enfranchisement, is essential to understand the experience of undocumented college students. The citizenship question not only establishes the formal boundaries of the spaces in which the rights and duties of citizens are in play; it also dictates which identities are included or excluded from the hegemonic community (Fenster, 2005). Cultural studies scholars have often approached belonging within frameworks of citizenship, based in the understanding that citizenship "manifests in numerous forms outside of its legal designation, as social citizenship, cultural citizenship, consumer citizenship, and sexual citizenship, among others" (Chávez, 2013, p. 13). Dehumanizing rhetoric regarding undocumented students in political discourse sends harmful messages that these students do not belong in the U.S. (or in universities) and should keep their identities hidden.

At the same time, there is also a danger of over-privileging the language of citizenship in grappling with the sense of belonging of undocumented youth. To reduce belonging to the language and logic of citizenship "reifies the status of modern nation-states that endow legal citizenship and through which most other modes of citizenship are articulated, even if only because of the use of the same term" (Chávez, 2013, p. 13). Similarly, relying exclusively on the language of citizenship to make sense of the experience of undocumented immigrants ignores the 
fact that " $[\mathrm{t}]$ he immigration enforcement apparatus extends well beyond the territorial border and border officials to encompass police, education, welfare, health care, and other workers who are frequently required to verify legal status and perform other immigration control-related functions" (Luibhéid, 2013, p. 8). In this sense, undocumented youth are tasked with navigating an intricate system of social, cultural, economic, political, and psychological barriers to their academic success and overall human development and personal well-being (Gonzales, 2011; Mangual Figueroa, 2017).

For example, in addition to the daunting material and legal challenges that undocumented students face in transitioning from K-12 to higher education (Chang, Torrez, Ferguson \& Sagar, 2017; Nienhusser \& Espino, 2017; Pérez, Cortés, Ramos, \& Coronado, 2010; Rincón, 2010a, 2010b; Serna et al., 2017), the social-emotional toll that the undocumented status has on an individual's life is well-documented (Ellis \& Chen, 2013; Gámez, Lopez, \& Overton, 2017). Many undocumented youth experience acute socioemotional distress due to their 'triple minority status': ethnic origin, lack of documentation, and economic disadvantages (Pérez et al., 2010). Likewise, the social identity formation of undocumented students can be particularly conflicting at times, as they may feel caught between their native culture and U.S. culture (Chang, 2011; Ellis, \& Chen, 2013; Pérez, Cortés, Ramos, \& Coronado, 2010). The socioemotional development of undocumented college students is likewise impacted by incidents of discrimination, fear of deportation, xenophobic sentiment, coupled with the systematic barriers preventing these students from financial aid and part-time employment (Pérez et al., 2010). Not surprisingly, the socioemotional/psychological stress experienced by undocumented youth has been linked to feelings of marginality, social identity confusion, and mental health issues such as depression and anxiety (Ellis \& Chen, 2013; Pérez, et al., 2010; Enriquez, 2011). 
Chang (2016) notes that while undocumented youth certainly face tremendous challenges, they also develop an "undocumented intelligence - that is - the knowledge, skills and intuition fostered by living as an undocumented person" (p. 2), a factor that plays a role in their sense of belonging.

In short, developing a sense of belonging can be a remarkably complex process for undocumented college students. This requires scholars to consider the cumulative impact of experiences across the students' lifespan to make sense of the challenges undocumented youth face in developing a sense of belonging as they transition into higher education spaces. This is the approach we take in organizing the findings section in this article, which follows after a discussion of the methods used in the study.

\section{Methods}

This paper draws from a youth participatory action research (YPAR) study that engaged undocumented participant co-researchers (PCRs). PCRs were initially recruited through a student organization specific to undocumented students via the primary investigator who attended two of these meetings at the invitation of the organization's student leaders. A snowball sampling method (Heckathorn, 1997) was used in subsequent recruiting efforts. This method yielded undocumented students that were DACA (Deferred Action for Childhood Arrivals) recipients and those that were not. DACA is a kind of administrative relief from deportation. The purpose of DACA is to protect eligible immigrant youth (meeting specific requirements) from deportation. DACA gives these undocumented immigrants: 1) temporary protection from deportation, and 2) a work permit. At the time of the study, the DACA program expired after two years and was subject to renewal thererafter. While not a path toward citizenship, the program 
symbolized hope and was a tangible source of temporary protection for undocumented youth. With regards to funding of undocumented students' higher education, Illinois was particularly proactive with legislative measures aimed at funding the higher education pursuits of undocumented students. In 2011, Governor Quinn signed the Illinois DREAM Act, whose goal was to make scholarships, college savings, and prepaid tuition programs available to undocumented students who graduated from Illinois high schools; it also created an Illinois DREAM fund to provide scholarships for undocumented students and made the State's 529 college savings and prepaid tuition programs available to Illinoisans with Individual Taxpayer Identification Numbers, regardless of whether they had social security numbers (Illinois Student Assistance Commission, 2012).

Even with these measures, however, prospective beneficiaries of the DREAM fund in Illinois were required to meet DREAM act eligibility stipulations; many eligible youth failed to apply or did not meet certain criteria, including some of the PCRs (e.g. they had not resided with parents or guardians while attending high school in Illinois; or had not attended a high school in Illinois for a least 3 years from the time of graduation or receiving the equivalent of a high school diploma (such as GED); or did not have a least one parent who immigrated to the United States). A similar disconnection between eligibility and application status was also evident at the national level. According to the Migration Policy Institute, at the time of DACA's launch in 2012 there were 1.2 million immediately eligible youth who met the program's requirements (Batalova, Hooker, Capps \& Bachmeier, 2014). However, it is estimated that about $45 \%$ of those individuals had not applied for DACA status by July 20, 2014. Among the possible reasons why eligible youth may not have done so are not being able to afford the $\$ 465$ initial application fee, fear of applying due to criminal history or inability to prove continuous presence in the United 
States, as well as individual barriers to program participation such as work and family responsibilities (idem). These figures hint at the diversity of experience and liminal status faced by DACAmented, DACA-eligible, and non-DACA students.

Regardless, all undocumented youth certainly faced nuanced challenges respective of their statuses in relation to DACA, and therefore we aimed to be as inclusive as possible with our recruitment of participants within the parameters of being undocumented. The PCRs DACA status at the time of the study is indicated in Table 1, along with other important background characteristics.

[Insert Table 1 about here.]

Youth participatory action research (YPAR) opens the role of researcher to students "as subjects and partners" in conducting research (Duncan-Andrade \& Morrell, 2008, p. 108). Rather than research being done on young people, YPAR students are positioned as the experts of their experiences and their schooling processes. Unlike traditional research approaches, YPAR students participate in every aspect of the research process. Through this experience, YPAR students learn new research skills, develop academic language, and begin to experiment with and initiate theory. They study issues that are relevant and meaningful to them and then apply those research findings to collectively take action to work toward social justice (Scott, Pyne, \& Means, 2014). YPAR is a powerful foundation for yielding knowledge that is authentically caring because it demonstrates the deepest regard for students' intellect and lived experiences. The ultimate goal is to center YPAR students as agents and producers of knowledge and so we use the term participant co-researchers to signify their dynamic roles. In the context of our study, PCRs applied research findings to inform their various social justice efforts/projects including but not limited to developing a DREAMers student group, taking political action at the state and 
nation's capitals, and choosing to remain silently active (Mendes \& Chang, 2019) by succeeding academically.

At the same time, engaging in YPAR research with undocumented students as PCRs is complex and laden with ethical considerations particularly as it relates to the reporting of data and the question of authorship. As a research team, we took these ethical questions to heart. While we were intentional in our efforts to balance the vulnerability and resilience of undocumented students, our main ethical responsibility, as indicated in our IRB, was to protect the identities of all participant co-researchers in the study. Given the precarious U.S. political climate and the chaotic events surrounding the repeal of DACA in 2017-2018 (Immigrant Legal Resource Center, 2018), the participant co-researchers erred on the side of caution and followed Chang, Mendes and Salazar's (2019) suggestion “to pause and think before making decisions that may or may not impact the safety and well-being of undocumented students. If in doubt, be conservative in any potential risk-taking." As a group, we discussed the authorship issue at length and agreed that protecting their status aligned with the spirit of our research and our initial agreements around anonymity. While the undocumented participant co-researchers had the option of providing nom de plumes in the publication of all work stemming from this data, all six of them decided against this approach. In this article they are identified by pseudonyms.

\section{Data Collection and Analysis}

This research took place from the fall of 2015 to the summer of 2017 at a community college in a metropolitan area in the state of Illinois. At the time of the study, Illinois provided instate tuition for undocumented students who had attended high school in the state for at least three years. The six undocumented PCRs engaged in this study for two years, during which they 
held weekly meetings of about 1.5 to 2 hours within the academic year (some weeks were missed due to academic breaks and college functions). The meetings centered on learning, exercising, and engaging our YPAR methodology via guest speakers, presentations, and discussions of shared assigned readings, supporting one another through the daily "ins-and-outs" of college life and debriefing current issues. Each meeting followed the same structure, beginning with PCRs sharing their highs and lows of the week, followed by a presentation, discussion, and/or modeling of an aspect of the YPAR process, and finishing up with sharing takeaways from that particular meeting.

Within this two-year time frame, the lead faculty co-researcher also interviewed individual PCRs using a phenomenological approach loosely based on Bevan's (2014) method of phenomenological interviewing, which consists of three separate but related interviews (contextualization, apprehending the phenomenon, clarifying the phenomenon). In the context of our study, these three aspects took form as: (1) a focused life history, (2) details of the phenomenon of being undocumented, and (3) a self-reflection on the meaning of the prior interviews. In some instances, interview \#2 and \#3 were combined in the same sitting when deemed appropriate, such as following the direction of the interview or when participant coresearchers were limited in time.

After data were collected, the PCRs concluded that, due to their demanding work and school schedules, they would allow the primary investigator of the research to lead an outside research team (the co-authors of this paper) to perform the bulk of the data transcribing, coding, and analysis, with the condition that the findings be shared with and agreed upon by the PCRs. The co-authors of this article are a socio-demographically diverse group of early-career and midcareer scholars, including undergraduate and graduate students, scholar-practitioners, and full- 
time faculty, all of whom share a commitment to social justice and to opening up spaces for the voices of undocumented youth. In attending to our positionalities in the data analysis process, our main priority was to work collaboratively, openly, and vulnerably, to ensure that the data analysis and interpretation presented an accurate representation of the participant co-researchers' histories and experiences.

The co-authors used Dedoose, a qualitative data analysis software with a highly collaborative interface, to conduct open coding on each transcript as well as identify emergent code patterns and dominant themes. Once the co-authors prepared a preliminary draft of the findings, the latter were shared with and approved by the six PCRs to ensure that the interpretation was in keeping with the reality of their experiences. Special attention was given to honoring the PCRs requests to omit sensitive information or information that might otherwise compromise their confidentiality.

\section{Findings}

As an inherently geographical concept, belonging connects matter to place, through practices of inhabitation boundary creation (Mee \& Wright, 2009), which signal that a particular collection of objects, people, practices, performances or ideas legitimately occupies a given space. In other words, belonging entails a condition in which one's presence in a space is possible, desirable, and legitimate. However, the narratives of the six PCRs continually pointed to a sense of "being-out-of-place" -that is, as being barred from entering, remaining in, or fully inhabiting given spaces as a result of their undocumented status. The following sections chronicle these dislocation experiences from two vantage points. First, we examine early dislocation experiences associated with the act of migrating and learning to navigate cultural symbols in the U.S., including those concerning language, gender, and race/ethnicity. These early 
experiences had a profound impact in the PCRs' ability to establish a sense of security and acceptance in educational settings and beyond. Next, we consider experiences upon graduating from high school, where dislocation took on added dimensions, as the PCRs prepared to apply to college and suddenly found themselves out-of-place in the support structures available to their peers. Significantly, differences in documentation status (e.g. DACA and non-DACA) marked some of the PCRs as more "in-place" within some formal student support structures. We then show how these multiple layers of vulnerability contributed to shaping the PCRs' experiences during their first year in college and highlight the PCRs' ability to seek and establish trusting relationships with others.

\section{Torn from Home: Migration as Dislocation from the Known World}

The initial moment of migration to the United States took place early in the lives of PCRs, ranging from early childhood through adolescence. While the reasons behind their families' migration varied, severe economic hardship and safety concerns were common catalysts for the decision. For some PCRs, especially those who were adolescents at the time of migration, this moment signified a powerful break from the world of their childhood. This, as we show in the sections below, had a lingering effect on their ability to maintain healthy and supportive relationships with their own families, let alone unfamiliar Others encountered in new environments.

A common phenomenon among the young children of immigrants in Mexico and other parts of Latin America is being left in the care of grandparents or other relatives when the biological parents initially migrate to the U.S. (Suárez-Orozco \& Suárez-Orozco, 2001). This was the case for PCRs like Tio. Raised in a loving home by his grandparents, Tio's contact with 
his parents was minimal for much of his childhood until they returned to take him back with them. Tio described his transition to a new country, and into close intimacy with parents he barely knew as a difficult process involved bridging healing the emotional rift caused by the long separation. "How do I put it in words? So, I hear my friends when they talk to their parents how close they are. They're super close. [W]ith my parents, I don't know, I just don't feel that connection as strong." Tio saw the estranged relationship with his biological parents as the lingering effects of his family's disjointed process of migration: "I knew that we're [in the U.S.] for a good reason [but] because of that good reason they messed up my life growing up."

A recurring theme among the PCRs was the shroud of family silence and secrecy surrounding the departure, and the deep uncertainty and helplessness that came with it. Cameron, for example, was thirteen when he and his family took what he thought was a vacation trip to the U.S. It was not until his parents started talking about enrolling him in school that he realized they were not going back to India, where he grew up in a joint household comprising parents, siblings, aunts, uncles, cousins, and grandparents. Losing that sense of connection a communality he was used to was deeply disconcerting, and he felt his own powerlessness keenly. "In my culture I have to obey my parents and stuff. I mean as a twelve, thirteen years old kid [I couldn't] make my own decision."

Once in the U.S., the PCRs had to learn the rules of different cultural structures, including those surrounding race, ethnicity, gender, and language. These structures were vastly different than those learned in their home culture(s); and deciphering these differences often led to a sense of being out-of-place. For example, the racial and ethnic demographics of the participants' urban communities surfaced as a critical factor in learning about their outsider status. Rosa found it "really hard to get used to the [U.S.] culture because... there is an, like, 
American way that people act and sometimes it's kind of hard to get used to. We feel different because we don't fit here." Similarly, Tio spoke of learning to navigate a high school system that was highly segregated along racial and socioeconomic lines:

[T]he high school that I went to is in the South side. It's full of gangs and all that stuff... Everybody wants to know what hood you're from or what do you do, who your parents are, who you know. Instead of becoming a friend, it's like, "who is my rival?" That's a constant feeling in the school.

As they learned the politics of identity in the U.S., the PCRs had to reconcile a sense of not fitting neatly into the categories, roles, and/or expectations imposed on them. Nayarin explained, 'I'm undocumented, and.... that's not the only label I'm given, you know? Like, I'm Hispanic. I belong to the minority group. I'm a woman, first-generation - and it's just like I have all these things put on me."

Some PCRs were also left with a sense of not living up to their parents' expectations for migrating in the first place. A prime example, Alejandro described a complex relationship with his parents. Despite having parents who were largely present in his life and being supported in a material sense, Alejandro felt his parents' strong practice of Catholicism and machismo created limitations to what he could do and who he could be in the U.S. In particular, Alejandro's parents constantly pressured him with "expectations [for him] as a man-a man that's going to get married and have children." During his interview, Alejandro disclosed his gay identity and that he remains closeted out of fear of failing his parents and forfeiting the sacrifices they made for him:

I don't know-The American Dream [is] the reason my parents migrated to the United States. They keep telling us that it was for a better future for us. I mean, I'm showcasing 
that. It's like, "you have a son [in college who] will be [transferring to] a prestigious university in the nation's capital.” But what I felt as a son when they [found out] my sexuality... That's not what they want—especially not my dad. So, I felt like, "you have a son that is succeeding...but he's gay."

Alejandro's struggle to balance his own needs and aspirations with those of his parents illustrates an important dimension and limitation of family motivational support among the undocumented college students in this study. Moreover, it demonstrates one way in which PCRs also experienced isolation among family members and, therefore, felt out-of-place on multiple levels.

The stress associated with this constant sense of being out-of-place often had severe psychological consequences, well beyond self-doubt and repressed expression of identities. While the PCRs described a range and varied forms of distress, Nayarin provided most severe example of the psychological consequences of dislocation. Nayarin detailed a prolonged state of loneliness, fueled by compounded stress at home and school. During her phenomenological interviews with the primary investigatory, she shared that she descended into a deep depression during her early adolescence. Without a peer or family support system, Nayarin was consumed by depression and began cutting herself in the sixth grade. When asked why she hurt herself, she explained:

Reality just hit me... Me and my mom didn't really communicate. Me and my sister didn’t communicate. I just feel real alone. I also got, like, I guess...bullied in school, like verbally... I didn't really have any friends. So, I just feel really alone. I feel like that's why I did it. 


\section{Leaving High School: Out-of-place in Legal and Financial Structures}

As previously mentioned, the PCRs experienced dislocation as a combination of cultural otherness and social isolation, which also instigated certain patterns of psychological distress and instability. Additionally, they were forced to contend with their "illegality;" some described growing up with a deep, ingrained fear of government detection. Luis shared that his parents “[a]lways live in fear. They came here illegally and they're always like, 'Oh my God, the cops are behind us!' They're always in panic mode when they see cops." However, the consequences of their undocumented status seemed to come to a head as they neared high school graduation and began applying for college.

Congruent with previous literature (Rincón 2010b; Suárez-Orozco, Bang, \& Kim, 2011), the transition from K-12 to higher education was a watershed moment for the PCRs. While the Supreme Court ruling of Plyler v. Doe (1982) ensured undocumented students' legal access to public education in grades K-12, as of this writing only twenty states and the District of Columbia have laws or policies allowing students who meet specific requirements, regardless of their immigration status, to pay in-state tuition rates at public postsecondary institutions (National Immigration Law Center, 2019). This means that many undocumented students face formidable challenges to cover the cost of a college education (Nienhusser \& Espino, 2017; Pérez et al., 2011; Rincon, 2010a, 2010b; Serna et al., 2017), including ineligibility for Free Application for Federal Student Aid (FAFSA) and other academic awards or scholarships.

As they lost the legal protections afforded by Plyler v. Doe upon graduating from college, the PCRs experienced a profound level of uncertainty. The legal conditions of the U.S. college opportunity structure instigated a spike in the salience of their undocumented status. Cameron recalled his panic when he first realized he needed a social security number for his college 
application: “Oh my, God! I'm not going to be able to go to college!” The lack of certain documentation was one of the main markers of their "illegitimate" status, as it had severe consequences in their ability to secure financial support. Luis recalled feeling overwhelmed when he had to take a class in high school on the college application process: "That's the only class that I feel at disadvantage because I [wasn't eligible for] government loans and I didn't have like all these opportunities that my friends had....[t]hat experience really opened my eyes." Because of their undocumented status, the PCRs had to navigate a highly ambiguous landscape of funding eligibility. They sometimes received conflicting information from wellintentioned institutional agents — that is, "high-status, non-kin, agents who occupy relatively high positions in [a] multiple dimensional stratification system, and who are well positioned to provide key forms of social and institutional support" to disenfranchised or otherwise vulnerable adolescents (Stanton-Salazar, 2011, p. 1066)—who were aware of the students' migratory status but not of its implications for accessing certain forms of student aid. This situation was further complicated by differences in eligibility depending on their specific status, such as whether they were covered by DACA or not. This was an important consideration, as the differences in opportunities for DACA and non-DACA holders can run deep. Cameron, one of the PCRs who did not hold DACA status at the time of the study, spoke fervently about the need to acknowledge the reality of undocumented students like himself:

[T] here is a division between the [DACA] documented people and the [DACA] undocumented people. People think if you're undocumented, 'Oh, you must have like DACA and then you should be able to do like all the other things.' But that's not true. I think it's really important for people to look at cases individually and with a very personal 
lens because not all undocumented students are the same. Not all undocumented students are DACA students.

Cameron further described what he saw as a sense of complacency among some DACA recipients who tried to distance themselves from migration reform activism. "I think some of the students or some of the people who have DACA are in this mindset that their fight is over" and that "they may try to camouflage, or they may try to be normalized in the group of nonundocumented people... because they're now safe, they don't have to worry about some of the things." Cameron's insights point to the importance of acknowledging that although the "undocumented student" category is often taken to denote a homogeneous group this is in fact not the case. The PCRs demonstrated a complex awareness of multiple dimensions of their identity (e.g., gender, religion, sexuality) and the multiple forms of oppression they faced in the United States. The differences between students who hold DACA status and those who do not represent an especially poignant example of the diversity inherent in this group, and which added to the layers of complexity that the PCRs had to navigate as part of their transition to college.

\section{The Cumulative Effect of Dislocation on College Interactions}

The previous sections highlight some of the experiences that led to the PCRs' sense of being out-of-place prior to attending college. Once in college, the PCRs navigated early peer interactions based on the survival instincts they developed as a result and which were often grounded in detachment, fear, and distrust of others. For example, Cameron, whose traumatic migration experience took him away from his beloved extended family in India, spoke casually yet with a keen awareness of the impermanence of human connections. This perspective shaped his approach to managing new relationships in college as mere acquaintances, with a degree of 
emotional detachment. "[It's] like all these places, the educational institutions that I go, I find really amazing people who are there; and so sometime, for some time, I feel attached and sadand then I move on."

Rather than detachment, other PCRs recalled a severe sense of mistrust upon meeting peers in college, especially along racial lines. Tio's experiences in high school had taught him that students from different racial/ethnic groups could only relate to each other as rivals. During his first weeks in college he found himself feeling suspicious when encountering groups of racially diverse students having friendly conversations, wondering, "Are they being forced to talk to one another or something?" Likewise, Nayarin expressed her profound discomfort "being around so many people," especially those she perceived as knowing their way around campus culture:

[I]t's something that it makes me really nervous because it's like I'm stuck with a bunch of White people.... I feel like people will judge me based off how we look. So, I feel very little when I'm around them.... They just seem more confident, more strong. They know what they're doing. [In contrast] I feel like I don't know what I'm doing, and I'm just always scared. I'm always scared and nervous.

Nayarin, whose profound isolation led to severe psychological and physical distress in high school, also described experiencing acute anxiety even around seemingly trivial tasks expected of college students, such as updating her emergency contact information on the college student portal. Although it is common for college students to be nervous about leaving family and friends behind to move into a college dorm, Nayarin's words suggest transitional stress and anxiety (see Goodman, Schlossberg, \& Anderson, 2006) can be exacerbated for undocumented students. This position is supported across the accounts offered by each of the six PCRs in this 
study, which collectively illustrate how even a slight unfamiliarity with the "ins-and-outs" of new institutional structures, requirements, and cultures can become overwhelming for undocumented students for whom a compounded sense of liminality, insecurity, and vulnerability has been a central feature of their lives.

\section{Healing and (re)Cultivating a Sense of Being-in-Place in College}

While the condition of being-out-of-place certainly played a major role in shaping the PCRs' lives, the effects of dislocation were by no means immutable or irreversible. Individually and collectively, the PCRs engaged in this study responded to the legal and sociopolitical circumstances of their lives with a complex battery of strategic actions — of which the most essential included actively seeking out navigational guidance and emotional support. In this regard, being able to establish trust-based relationships with others was a key element of their journeys to (re)cultivate meaningful connections to a community in which a sense of being-inplace was possible.

Salient in the data was the PCRs' actively seeking opportunities to connect with and give back to their local communities. This is in keeping with previous research showing that to combat their marginalized/criminalized liminal status undocumented college students actively seek ways to embed themselves in their communities (De Genova, 2002; Muñoz \& Aleman, 2016; Pérez et al., 2010). The experience of being out-of-place heightened their ability to empathize with the plight of others and compelled them to take on community service activities as early as middle school. Rosa expressed her commitment to helping others kept her from feeling overwhelmed because it anchored her to a sense of purpose. "I do a lot of community service [because] I realized I wanted to do something like for my community, for the immigrant 
community." Luis similarly offered, "The same support system that I received from my community, I kinda wanna give that back to other people to let them know that they're not by themselves."

Moreover, in the college setting, PCRs were acutely aware of the importance of establishing connections to trusted peers and faculty, who understood their unique circumstances as undocumented students through the college application process and first-year experience. Expressed needs ranged from support with navigating DACA-related concerns (e.g. eligibility, application, activism and so on) and knowing what information was safe to share with others to dealing with discrimination linked to their undocumented status. Cameron stressed the importance of "meet[ing] the right kind of people and make the right kind of friends who support [us] as undocumented [individuals], who support [us] as like a minority, who understand like the issues that affect [us]." Similarly, Nayarin expressed the critical need for staff and faculty to educate themselves about the reality of undocumented students' lives and circumstances. Faculty and staff who were open to and knowledgeable about their circumstances were essential to making her and her undocumented peers feel safe. "I think that's why so many people went to [Professor's name redacted], undocumented or not undocumented. She was always there to listen to them and she never judged them. She always provided support and an answer to our problems." Likewise, high school and college advisers were noted for their commitment to helping undocumented students navigate the college application process, gain access to financial aid and other critical resources, and serving as a source of emotional support. Luis shared the pivotal role of teachers and school counselors who were "truly are passionate for what they do" and for creating the time and space to empower students like himself. 
Likewise, exposure to and membership in meaningful and safe communities played a significant role in helping participants (re)cultivate a sense of being-in-place. As previously mentioned, Tio was initially very suspicious of his college classmates; a deep skepticism that developed after experiencing years of peer aggression and competition in high school, where cliques of students maintained inflexible racial boundaries. Gradually, he learned to believe these new positive student interactions were genuine, and he became more open to trusting his peers. "It made me realize there's more people out there. Everyone is welcoming, not everyone is bad. It's okay to be friends." His experience speaks to the great transformational potential of supportive, inclusive, safe college climates in promoting connection to others and expanding the students' academic and personal horizons.

\section{Discussion}

The condition of dislocation that permeated the narratives of co-researcher participants is implied in the expression "ni de aqui ni de allá," often referenced in the literature on undocumented students (e.g. Hilburn, 2014) to signal their limbo-like existence, neither fully belonging to their country of origin nor to the United States. More broadly, the term "dislocation" is mentioned in the literature on immigrant youth and is frequently used to hint at the economic or political upheaval that served as a catalyst for migration, such as war or extreme economic inequality and related violence in the immigrants' countries of origin (Seif et al., 2014). However, while "dislocation" is frequently used as a useful shorthand to connote the traumatic nature behind the decision to leave one's place of origin, the concept itself is rarely examined in greater detail. The findings of this study help us move beyond a disembodied and abstracted notion of belonging among undocumented students by illuminating the ways in which dislocation impacts their lives, including at the crucial moment of transitioning to college. 
As shown in the findings, learning to establish a sense of belonging within the college context was an ongoing and often fraught process for the PCRs which required them to confront the cumulative and sustained impact of the many moments of dislocation in their lives. Originating in multiple experiences of dislocation and (re)settlement, participants described a "fear and distrust of others" that guided their general social interactions and, more specifically, influenced how they engaged with peers and institutional agents in the transition(s) to and through college. While this fear and distrust manifested itself in the transition to higher education, we find, like scholars such as Mangual Figueroa (2017), that the former tend to originate much earlier in the lives of undocumented students.

It is worth noting that the PCRs were not passive victims of dislocation. Individually and collectively, they survived adverse childhood experiences and successfully navigated a number of complex life-transitions, long before arriving to a college campus. Their agency was instrumental to rebuild a sense of "being-in-place." In this regard, the PCRs were deeply embedded in local communities and "giving back" through various forms of service was central to their sense of wellbeing. Nonetheless, even with a strong commitment to civic engagement, undocumented students are not guaranteed the same rights as legal citizens or residents (Pérez et al., 2010). The legal challenges to their full membership into American society remain real and daunting, as do the lasting consequences of living and learning with/in the liminal spaces and layered trauma(s) of dislocation. As concluded by Gonzales, Suarez-Orozco, and DediosSanguineti (2013), the cumulative stress of a hostile social and political climate, along with the ever-present fear of deportation, the burden of stigmatized identities, and considerable limitations to their participation as full members of society, can take a severe toll on undocumented youth's mental and emotional health, as shown in the PCRs narratives'. 
These findings lend support to prior literature documenting the "triple-minority" status of undocumented students associated with their ethnic origin, lack of documentation, and economic disadvantages (Pérez et al., 2010, p. 36). The findings also extend previous research on the developmental impact of liminal status (e.g., Suárez-Orozco et al., 2011) by (re)locating and examining the origins and evolution of liminality. Traced from the vantage point of college students on the verge of the transition(s) to and into college, the findings illustrate a number of social, cultural, and psychological experiences of dislocation that undocumented students may encounter across their young lives.

In this regard, the article contributes to literature exploring educational inequities related to undocumented status from a lifespan perspective. The focus on dislocation experiences across the lifespan brings into greater focus the unique social, emotional, and material challenges faced by undocumented students - including some that hint at the intersectionality of experiences and backgrounds within this population, an aspect that often gets lost in the scholarship. Dislocation entails a degree of vulnerability and liminality that is not necessarily encompassed in current models of student development theory, nor considered in institutional support structures created with majority-population students in mind. This is not to say that such vulnerability is unique or exclusive to students of undocumented status - one could perhaps make a similar claim about students in homeless or near-homeless situations, those who have experienced domestic abuse or any other extraordinary condition with the potential for severe instability and physical, mental, or emotional trauma. Yet the specificity of these circumstances matter, and there is a clear need for the literature to delve deeper into the experiences of these student populations. By examining the dislocation experiences of undocumented students, we shed light on unexplored aspects of student development scholarship. 


\section{Conclusion}

Despite the turbulence of dislocation, or perhaps through it, the PCRs in this study developed rich insights into who they are and how to regain a sense of belonging in the spaces they inhabit. We offer this (re)location of agency as, perhaps, the most relevant finding in our current study, holding many implications for policy and practice, especially when we consider the significant impact that institutional agents and trusted mentors can have in supporting undocumented youth as they navigate a complex and uncertain U.S. sociopolitical landscape. As illustrated, connection with trusted others (both in personal and institutional spaces) played a powerful role in enabling PCRs to challenge and redefine experiences of dislocation and what it means to belong. This is in keeping with prior scholarship showing that support from institutional agents and community members is crucial to the success of college students with an undocumented status, as is guidance from social support groups, student organizations, peers, and family members (Covarrubias \& Lara, 2014; Enriquez, 2011). This YPAR project sought to provide participants with an opportunity to discuss and explore the complexity of their experience as undocumented scholars. We believe similar participatory initiatives can provide important channels to incorporate the voices and experiences of undocumented college students in higher education policy and practice.

Our findings point to the imperative need for schools and universities to provide dedicated support to students with undocumented status. There is a need for explicit policies that allow institutional agents to learn about and to provide adequate supports for undocumented students. In keeping with the PCRs' narratives, prior research has demonstrated that many undocumented students reported that university staff were not aware of institutional policies concerning migratory status and had limited professional development associated with 
undocumented student issues (Contreras, 2009). Because institutional agents often lack the knowledge and training needed to support undocumented students, many students have a difficult time deciding who to trust with their status, causing many to avoid interactions with university staff (Contreras, 2009; Stebleton \& Aleixo, 2015). The hiring and training of institutional agents — including mental health staff — with a thorough understanding of this population (including its inherent diversity of backgrounds and experiences) could provide important spaces of support that are critical for the transition to college.

Likewise, K-12 and postsecondary institutions must consider their role in the shaping the experiences of undocumented students through the types of campus climates they foster, and the extent to which they are truly welcoming of marginalized students more broadly. As the narratives in this article illustrate, undocumented students are far from a homogeneous group. Meeting the needs of this population calls for specialized training of staff (Gámez, Lopez, \& Overton, 2017; Nienhusser \& Espino, 2017; Stebleton, \& Aleixo, 2015) to understand the lived experiences of undocumented students, and the policies that impact them at multiple levels. Stebleton and Alexio (2015) stress the need for staff to "become more familiar with the needs, issues, and assets of immigrant students and immigrant resources to best support them" (p. 268). To this list, we add including sensitivity to both the diversity inherent in this population as well as the multiple manifestations of dislocation that undocumented youth may experience within and beyond educational settings. By equipping staff with culturally relevant knowledge, skills, and attitudes, future undocumented students may receive the institutional support and mentorship needed to feel validated and safe, as any student should.

\section{References}


Abrego, L. J. (2006). “I can’t go to college because I don't have papers": Incorporation patterns of Latino undocumented youth. Latino Studies, 4(3), 212-231.

Bevan, M. T. (2014). A method of phenomenological interviewing. Qualitative Health Research, 24(1), 136-144.

Bronfenbrenner, U. (1994). Ecological models of human development. Readings on the development of children, 2(1), 37-43.

Chang, A. (2016). Undocumented Intelligence: Laying Low by Achieving High as a Good Noncitizen Citizen. Race, Ethnicity and Education.

DOI:10.1080/13613324.2016.1168539

Chang, A. (2011). Undocumented to Hyperdocumented: A Jornada of Protection, Papers and PhD Status. Harvard Educational Review, 81(3), 508-520.

Chang, A., Mendes, J., \& Salazar, C. (2019). Qualitative methodological considerations for studying undocumented students in the United States. In G. Noblit (Ed.), The Oxford encyclopedia of qualitative research methods in education. Oxford, UK: Oxford University Press.

Chang, A., Torrez, M., Ferguson, K. \& Sagar, A. (2017). Figured worlds \& American dreams: an exploration of agency and identity among Latinx undocumented students. Urban Review. DOI 10.1007/s11256-017-0397-x

Chávez, K. R. (2013). Queer migration politics: Activist rhetoric and coalitional possibilities. Chicago, IL: University of Illinois Press.

Contreras, F. (2009). Sin papeles y rompiendo barreras: Latino students and the challenges of persisting in college. Harvard Educational Review, 79, 610-631. 
Covarrubias, A., \& Lara, A. (2014). The undocumented (im)migrant educational pipeline: The influence of citizenship status on educational attainment for people of Mexican origin. Urban Education, 49(1), 75-110.

Denzin, N., \& Lincoln, Y. (2000). Handbook of qualitative research ( $2^{\text {nd }}$ ed.). Thousand Oaks, CA: Sage.

Duncan-Andrade, J. M. R. \& Morrell, E. (2008). The art of critical pedagogy: Possibilities for moving from theory to practice in urban schools. New York, NY: Peter Lang.

Ellis, L. M., \& Chen, E. C. (2013). Negotiating identity development among undocumented immigrant college students: A grounded theory study. Journal of Counseling Psychology, $60(2), 251-264$.

Enriquez, L. E. (2011). "Because we feel the pressure and we also feel the support": Examining the educational success of undocumented immigrant Latina/o students. Harvard Educational Review, 81(3), 476-500.

Fenster T. (2005). Gender and the city: the different formations of belonging. In L. Nelson and J. Seager (Eds.), A companion to feminist geography (pp. 242-257). Malden, MA: Blackwell.

Fish, J., \& Syed, M. (2018). Native Americans in higher education: An ecological systems perspective. Journal of College Student Development, 59(4), 387-403.

Gámez, R., Lopez, W., \& Overton, B. (2017). Mentors, resiliency, and ganas: Factors influencing the success of DACAmented, undocumented, and immigrant students in higher education. Journal of Hispanic Higher Education, 16(2), 144-161.

Gonzales, R. G. (2011). Learning to be illegal: Undocumented youth and shifting legal context in the transition to adulthood. American Sociological Review, 76(4), 602-19 
Gonzales, R. G., Perez, J. B., \& Ruiz, A. G. (2016). "Ni de aqui, ni de allá”: Undocumented immigrant youth and the challenges of identity formation amid conflicting contexts. In $\mathrm{H}$. D. Romo \& O. Mogollon-Lopez (Ed.), Mexican migration to the United States: Perspectives from both sides of the border (pp. 119-139). Austin, TX: The University of Texas Press.

Gonzales, R. G., Suárez-Orozco, C., \& Dedios-Sanguineti, M. C. (2013). No place to belong: Contextualizing concepts of mental health among undocumented immigrant youth in the United States. American behavioral scientist, 57(8), 1174-1199.

Illinois Student Assistance Commission. (2012). Illinois Dream Act. Springfield, IL: Illinois Student Assistance Commission. Retrieved February 26, 2020 from https://www.isac.org/home/illinois-dream-act.html

Immigrant Legal Resource Center (2018). DACA Timeline Infographic. San Francisco, CA: ILRC. Retrieved February 16, 2020 from https://www.ilrc.org/daca-timeline-infographic. Hausmann, L. R., Schofield, J. W., \& Woods, R. L. (2007). Sense of belonging as a predictor of intentions to persist among African American and White first-year college students. Research in Higher Education, 48(7), 803-839.

Heckathorn, D. (1997). Respondent-driven sampling: A new approach to the study of hidden populations. Social Problems, 44, 174-199.

Heeren, G. (2015). The status of nonstatus. American University Law Review, 64(5), 1115-1182.

Hurtado, S., Alvarado, A. R., \& Guillermo-Wann, C. (2015). Creating inclusive environments: The mediating effects of faculty and staff validation on the relationship of discrimination/bias to students' sense of belonging. Journal Committed to Social Change on Race and Ethnicity, 1(1) 60-81. 
Johnson, D., Soldner, M., Leonard, J., Alvarez, P., Inkelas, K., Rowan-Kenyon, H., \& Longerbeam, S. (2007). Examining sense of belonging among first year undergraduates from different racial/ethnic groups. Journal of College Student Development, 48(5), 525 242.

Luibhéid, E. (2013). Pregnant on Arrival: Making the Illegal Immigrant. Minneapolis, MI: University of Minnesota Press.

Mangual Figueroa, A. (2017). Speech or silence: Undocumented students' decisions to disclose or disguise their citizenship status in school. American Educational Research Journal, $54(3), 485-523$.

Mee, K., \& Wright, S. (2009). Geographies of belonging. Environment and Planning 41, 772779.

Mendes, J., Chang, A. (2019). Undocumented and afraid: Expanding the definition of student activism. In D. Morgan \& C.H.F. Davis (Eds.), Student activism, politics, and campus climate in higher education, (pp. 60-76). New York, NY: Routledge.

Muñoz, A., \& Alleman, N. F. (2016). Status convergence: A sociological investigation of undocumented students' legal and collegiate social statuses. Journal of College Student Development, 57(8), 990-1008.

National Immigration Law Center (2019). State laws and policies on access to higher education for immigrants. Los Angeles: National Immigration Law Center.

Negrón-González, G. (2014). Undocumented youth activism as counter-spectacle: Civil disobedience and testimonio in the battle around immigration reform. Aztlán: A Journal of Chicano Studies, 40(1), 87-112. 
Nienhusser, H. K., \& Espino, M. M. (2017). Incorporating undocumented/DACAmented status competency into higher education institutional agents' practice. Journal of Student Affairs Research \& Practice, 54(1), 1-14.

Ostrove, J. M., \& Long, S. M. (2007). Social class and belonging: Implications for college adjustment. The Review of Higher Education, 30(4), 363-389.

Patton, L. D., Renn, K. A., Guido, F. M., \& Quaye, S. J. (2016). Student development in college: Theory, research, and practice (3rd ed.). San Francisco, CA, US: Jossey-Bass.

Pérez, W., Cortés, R. D., Ramos, K., \& Coronado, H. (2010). “Cursed and blessed”: Examining the socioemotional and academic experiences of undocumented Latina and Latino college students. New Directions for Student Services, 131, 35-51.

Pérez, W., Espinoza, R., Ramos, K., Coronado, H. M., \& Cortes, R. (2009). Academic resilience among undocumented Latino students. Hispanic Journal of Behavioral Sciences, 31(2), 149-181.

Perez, W., Espinoza, R., Ramos, K., Coronado, H., \& Cortes, R. (2010). Civic engagement patterns of undocumented Mexican students. Journal of Hispanic Higher Education, $9(3), 245-265$.

Plyler v. Doe, 457 U.S. 202, 102 S. Ct. 2382, 72 L. Ed. 2d 786 (1982).

Probyn, E. (1996). Outside belongings. New York, NY: Routledge.

Quaye, S. J. \& Harper, S. R.(2014). Student engagement in higher education: Theoretical perspectives and practical approaches for diverse populations. New York, NY: Routledge.

Renn, K. \& Arnold, K. D. (2003). Reconceptualizing research on college student peer culture. The Journal of Higher Education, 74, 261-291. 
Rincón, A. (2010a). ¡Si se puede!: Undocumented immigrants' struggle for education and their right to stay. Journal of College Admission, (206), 13-18.

Rincón, A. (2010b). Undocumented immigrants and higher education. iSi se puede! El Paso, TX: LFB Scholarly Publishing.

Rubin, M. (2012). Social class differences in social integration among students in higher education: A meta-analysis and recommendations for future research. Journal of Diversity in Higher Education, 5(1), 22-38.

Scott, M. A., Pyne, K. B., \& Means, D. R. (2014). Approaching praxis: YPAR as critical pedagogical process in a college access program. The High School Journal, Winter 2014, $138-157$.

Serna, G. R., Cohen, J. M., \& Nguyen, D. H. K. (2017). State and institutional policies on instate resident tuition and financial aid for undocumented students: Examining constraints and opportunities. Education Policy Analysis Archives, 28(14-18), 1-22.

Stanton-Salazar, R. D. (2011). A social capital framework for the study of institutional agents and their role in the empowerment of low-status students and youth. Youth \& Society, 43(3), 1066-1109.

Stebleton, M. J., \& Aleixo, M. B. (2015). Examining undocumented Latino/a student interactions with faculty and institutional agents. Journal of Hispanic Higher Education, 14(3), 256273.

Stephens, N. M., Fryburg, S. A., Markus, H. R., Johnson, C. S., \& Covarrubias, R. (2012). Unseen disadvantage: How American universities' focus on independence undermines the academic performance of first-generation college students. Journal of Personality and Social Psychology, 102(6), 1178-1193. 
Strayhorn, T. L. (2012). College students'sense of belonging: A key to educational success for all students. New York, NY: Routledge.

Strayhorn, T. L. (2019). College students' sense of belonging: A key to educational success for all students $\left(2^{\text {nd }}\right.$ ed). New York, NY: Routledge.

Suárez-Orozco, C., \& Suárez-Orozco, M.M. (2001). Children of immigration. Cambridge, MA: Harvard University Press.

Suárez-Orozco, M. (1987). "Becoming somebody": Central American immigrants in U. S. innercity schools. Anthropology \& Education Quarterly, 18(4), 287-299.

Vaccaro, A., \& Newman, B. (2016). Development of a sense of belonging for privileged and minoritized students: An emergent model. Journal of College Student Development, $57(8), 925-942$.

Westheimer, J. \& Kahne, J. (2004). What kind of citizen? The politics of educating for democracy. American Educational Research Journal 41(2), 237 - 269.

Zhong, J., \& Batalova, J. (2019, April). How many unauthorized immigrants graduate from U.S. high schools annually? Washington, DC: Migration Policy Institute. 
Table 1: Key background information on Participant Co-Researchers (PCRs)

\begin{tabular}{ll}
\hline Pseudonym & Background Information \\
\hline Rosa & Non-DACA status at time of study. Migrated to the United States at fifteen \\
& years old from Guatemala. Rosa's migration experience with her mother and \\
& sister spanned six months. Rosa encountered experiences with depression and \\
& wrote letters to herself as a way to talk about and process her feelings and \\
& experiences. She kept her undocumented status a secret not trusting people \\
& and fearing deportation. When asked to describe herself Rosa included the \\
& words faith, justice, determination, and hard work. \\
& \\
Luis & DACA status at time of study. Immigrated from Mexico at four years old. Luis \\
& fearful of the police discovering that he and his family were illegal. When \\
& asked to describe himself Luis selected the words outgoing, hard-working, \\
& active, calm, and community-oriented.
\end{tabular}

Nayarin DACA status at time of study. Immigrated from Mexico at five years old. Nayarin described experiencing deep social anxiety. Nayarin felt her ability to apply for scholarships and study abroad were limited due to her undocumented status. When asked to describe herself, Nayarin shared that she was shy, selfconscious, a good listener, observant and non-judgemental. Nayarin plans for the future include obtaining a $\mathrm{PhD}$ in psychology, traveling the world and working with children.

Cameron Non-DACA status at time of study. Immigrated from Hyderabad, India at thirteen years old. Many of his early schooling experiences were difficult because of his limited English proficiency. Dreams for the future include being a good person and a longing for Islam to not be thought of so negatively. When asked to describe himself, Cameron shared that he is honest, friendly, fearless, and social justice oriented.

Alejandro DACA status at time of study. Immigrated from Mexico at three years old. Had difficulty reconciling his experience with labels and categories (e.g. male, gay, Catholic). Felt that his achievement in school was silenced due to his undocumented status. Consequently, Alejandro felt compelled to do well in school for the same reason. He felt institutions were taking his identity from him in feeling that he had to hide his undocumented status. His future goals include graduating with a bachelor's degree from Georgetown University and working in government and/or going to law school.

Tio

DACA status at time of study. Migrated to the United States at the age of seven from Mexico. He was raised by his grandparents and without a strong connection to his parents. Lived in a community with a lot of gangs and hostility. Tio's transition from high school to community college exposed him to an environment without hostility and competition from his peers and made 
him more open-minded. Tio found purpose and fulfillment in being a teacher in karate. Tio has an interest in neuroscience and industrial psychology. 